\title{
ANATOMICAL VARIATION IN BRANCHING PATTERN OF BRACHIAL PLEXUS AND ITS CLINICAL SIGNIFICANCE
}

\section{G Anwer Khan *1, Shekhar K Yadav ${ }^{1}$, A Gautam ${ }^{1}$, S Shakya ${ }^{1}$, R Chetri ${ }^{2}$.}

${ }^{* 1}$ Department of Anatomy, Chitwan M edical College, CM C, Bharatpur, Nepal.

${ }^{2}$ Department of Anatomy, College of M edical sciences, CMS, Bharatpur, Nepal.

\section{ABSTRACT}

\begin{abstract}
Background: Anatomical variations in the branching pattern of the brachial plexus have been described in humans by many authors; however these have not been extensively catalogued. The aim of the study was to describe and observed anomalies in distribution of the branch (branching pattern) derived from the cord of brachial plexus, both in its supraclavicular and infraclavicular parts.

Methods: This study included thorough dissection of 60 brachial plexuses which belonged to 30 cadavers (male: female ratio $=28: 02$ ) with age range of 20-60 years, obtained from the Department of Anatomy, College of Medical Sciences (CM S-TH), following standard guidelines.

Results: Out of 60 limbs dissected in present study, Normal branching pattern of the posterior cord was encountered in $52(86.67 \%)$ limbs, the remaining $8(13.33 \%)$ being variants in one form or the other. The upper subscapular nerve, the thoracodorsal nerve, the lower subscapular nerve and the axillary nerve were found to arise normally in $91.66 \%, 96.66 \%, 96.66 \%$ and $98.33 \%$ of the limbs respectively.

Conclusion: The present study carried out on adult human cadavers revealed some rare variations in the branching pattern of the brachial plexus. These variations are of clinical significance are very useful for the anatomists, radiologists, anesthesiologists, neurosurgeons and orthopedic surgeons and general surgeons.

KEY WORDS: Brachial plexus, branching pattern, Anatomical variation.
\end{abstract}

Address for Correspondence: Dr. Gulam Anwer Khan, Department of Anatomy, Chitwan M edical College, CM C, Bharatpur, Nepal. E-M ail: aanwer227@gmail.com

\begin{tabular}{|c|c|c|}
\hline \multicolumn{3}{|c|}{ Access this Article online } \\
\hline \multirow{2}{*}{ Quick Response code } & \multicolumn{2}{|c|}{$\begin{array}{l}\text { Web site: International Journal of Anatomy and Research } \\
\text { ISSN 2321-4287 } \\
\text { www.ijmhr.org/ijar.htm }\end{array}$} \\
\hline & $\begin{array}{l}\text { Received: } 16 \text { Nov } 2016 \\
\text { Peer Review: } 17 \text { Nov } 2016 \\
\text { Revised: None }\end{array}$ & $\begin{array}{l}\text { Accepted: } 01 \text { Dec } 2016 \\
\text { Published (O): } 31 \text { Jan } 2017 \\
\text { Published (P): } 31 \text { Jan } 2017\end{array}$ \\
\hline
\end{tabular}

\section{INTRODUCTION}

Anomalies of brachial plexus related to its formation, branching pattern and relations with major vessels are fairly common. Normally the brachial plexus is formed by lower four cervical ventral rami ( $\mathrm{C} 5, \mathrm{C} 6, \mathrm{C} 7, \mathrm{C} 8)$ and greater part of the first thoracic ventral ramus (T1). It consists of roots, trunks, divisions and cords (lateral cord, medial cord and posterior cord)[1].

Sometimes $\mathrm{C} 4$ roots joins with $\mathrm{C}$, when plexus is called pre-fixed type. On occasions $\mathrm{T} 2$ roots joins with $\mathrm{T} 1$ with disappearance of $\mathrm{C} 4$ roots; this forms the post-fixed type of plexus. Branches of the brachial plexus are divided into supraclavicular and infraclavicular branches, supraclavicular branches are four (dorsal scapular nerve $\mathrm{C} 5$, a branches to join the phrenic nerve $\mathrm{C} 5$, long thoracic nerve $\mathrm{C} 5, \mathrm{C} 6, \mathrm{C} 7$, muscular branches to longus colli and scalene) from roots and two from upper trunk (nerve to subclavius and suprascapular nerve); infraclavicular branches are three from lateral cord (lateral pectoral nerve, musculocutaneous nerve and lateral root of median nerve), five from medial 
cord (medial pectoral nerve, medial cutaneous nerve of forearm, medial cutaneous nerve of arm, ulnar nerve $\mathrm{C} 7, \mathrm{C} 8, \mathrm{~T} 1$ and medial root of median nerve) and five from posterior cord (upper subscapular nerve $\mathrm{C} 5, \mathrm{C} 6$, thoracodrsal nerve $\mathrm{C} 6, \mathrm{C} 7, \mathrm{C8}$, lower subscapular nerve $\mathrm{C} 5, \mathrm{C} 6$, axillary nerve $\mathrm{C} 5, \mathrm{C} 6$, and radial nerve $\mathrm{C} 5, \mathrm{C} 6, \mathrm{C} 7$, C8, T1) [2]. The anomalous formation, branching pattern and relations of brachial plexus can be explained in the light of embryo genic development.

The upper limb buds lie opposite the lower five cervical and upper two thoracic segments. As soon as the buds form, the ventral primary rami of the spinal nerves penetrate into the mesenchyme of limb bud. Immediately the nerves enter the limb bud, they establish intimate contact with the differentiating mesodermal condensations and the early contact between nerve and muscle cells is a prerequisite for their complete functional differentiation [2-4].

The knowledge of variation in the formation, branching pattern and relation of brachial plexus is mainly helpful for anesthesiologists and surgeons for improved guidance during infraclavicular block procedures, surgical approaches for brachial plexus region tumors and orthopedic treatment of the diseases of cervical spine and excision of cervical rib. This type of knowledge is also very useful for neurosurgeons for treating tumors of nerve sheaths such as schwannoma, neurofibroma and non-neuronal tumors like lipoma especially in the axillary region $[5,6]$.

During surgical procedures of the axilla and the shoulder, a surgeon is exposed to the topographical anatomy of the neural structures and awareness of such variations may be of immense help in order to avoid inadvertent nerve injuries. Knowledge of such anomalies is also important during treatment of fractures and neurotization of brachial plexus lesions [6]. Taking into consideration the commonness of occurrence of variations in the branching pattern of brachial plexus and its paramount clinical and surgical importance, the present study was undertaken in order to find the more commonly encountered anomalies as well as the rare variations of brachial plexus. Further, an attempt was made to explain these variations in the light of embryo genic development. Finally, all the variations observed in the current study were analyzed in clinical and surgical perspective.

\section{MATERIALS AND METHODS}

The study comprised of 60 upper limbs which belonged to 30 adult human cadavers of known sex [male: female ratio 28:02], obtained from mortuary of the Department of Anatomy, College of Medical Sciences and Teaching Hospital, Bharatpur, Chitwan, during the period between March 2009 to October 2012. The cadavers used in the current study were serialized from 1-30 with the suffixes ' $M$ ' for male, ' $F$ ' for female, ' $R$ ' for right and ' $L$ ' for left. Ethical approval was granted by the (Institutional Review Committee) of College of Medical Sciences and Teaching Hospital, Bharatpur, Chitwan.

The limbs of all cadavers were meticulously dissected (axilla, arm, cubital fossa, forarm and palm). The brachial plexus was dissected and exposed according to the methods described by Romanes in Cunningham's Manual of Practical Anatomy. All its roots, trunks, divisions, cords and branches were cleaned and the mode of their formation, branching pattern and relations with major blood vessels of upper limbs (especially axillary and brachial arteries) were observed and noted. In each cadaver, both the upper limbs were dissected to note whether the variation, if any, was present unilaterally or bilaterally. The distances were measured at different branches of posterior cord of brachial plexus from origin of the parent cord; a thread was kept along the length of that part and was marked with Indian ink at designated points. The thread which was thus marked was lifted off the dissection area and spread along a graduated metric scale to measure the length in centimeters scale. All findings with regard to the variations in the formation of trunks and cords of brachial plexus, distribution of the branches derived from the cords and anomalous relationship of trunks, cords and their branches with major blood vessels of the upper limb were documented and recorded. Statistical analysis was done wherever applicable. 


\section{OBSERVATION AND RESULTS}

In the present study, all variations related to the branching pattern of brachial plexus were found only in relation to posterior cord, branching pattern of medial and lateral cord being normal in all cadavers. The normal branching pattern of the posterior cord was encountered in 50 (83.33\%) limbs in the present study, the remaining $10(16.66 \%)$ being variants in one form or the other ,All variations related to branching pattern of brachial plexus were noted in male cadavers.

(i) The Upper Subscapular Nerve: In the present study, the upper subscapular nerve was seen to arise normally from the posterior cord in 55 $(91.6 \%)$ limbs but in the remaining 5 limbs $(8.33 \%)$, it originated from the posterior division of the upper trunk (root value $\mathrm{C} 5,6$ ), 2 in right and 3 in left side of male cadavers with approximate age of $25,40,45,60$ and 35 years respectively.

(ii) The Thoracodorsal Nerve: The thoracodorsal nerve depicted a normal origin in 58 (96.67\%) limbs in the present study, it being variant in 2 limbs (3.33\%), where it was seen to be coming from the posterior division of the upper trunk (root value- $\mathrm{C} 5,6$ ), one in right and one in left side of male cadavers with approximate age of 20 and 35 years.

(iii) The Lower Subscapular nerve: The lower subscapular nerve took its abnormal origin from the axillary nerve in 2 right limbs (3.33\%) of male cadavers with approximate age of 60 and 45 years, it being normal in the rest of the 58 (96.67\%) limbs.

(iv) The Axillary Nerve: The axillary nerve, being normal in origin as one of the terminal branches of the posterior cord in 59 (98.33\%) limbs in the present study, was variant in one (1.66\%) left limb of a male cadaver with approximate age of 30 years, it was found to originate from the posterior division of the upper trunk (root value-C5, 6).

An important observation of the present study was that all the variant origins of the different branches of the posterior cord were seen in the male sex only. The pattern in females was perfect as was described in the text books. Also, all the variants of the upper subscapular, the thoracodorsal and the axillary nerves took origin from the posterior division of the upper trunk but the variant lower subscapular nerve originated from the axillary nerve.

The Distances of Different Branches of the Posterior Cord from the Origin of the Parent Cord: Table No. 1 depicts the distances of the different branches of the posterior cord from the origin of the parent cord. It is evident from Table No. 3 that the posterior cord gave off the upper subscapular nerve at an average distance of 0.96 $\mathrm{cm}$. (Rt $-0.96 \mathrm{~cm}$; Lt $-0.96 \mathrm{~cm}$.) from the point of its formation, the thoracodorsal nerve, at an average distance of $1.18 \mathrm{cms}$. (Rt - $1.10 \mathrm{cms}$.; Lt - $1.26 \mathrm{cms}$.) And the lower subscapular nerve, at an average distance of $1.47 \mathrm{cms}$. (Rt - 1.40 cms.; Lt $-1.55 \mathrm{cms}$.) From the point of their formation. Then, it bifurcated terminally into the axillary nerve and the radial nerve at an average distance of $2.02 \mathrm{cms}$. (Rt - $1.86 \mathrm{cms;}$ $\mathrm{Lt}-2.20 \mathrm{cms}$.) from the point of its formation. However, the upper subscapular, the thoracodorsal and the axillary nerves which had their variant origin from the posterior division of the upper trunk, arose at an average distance of 2.0 $\mathrm{cm} ., 2.15$ and $3.40 \mathrm{cms}$ respectively from the formation of the posterior division while the lower subscapular nerve arose from the axillary nerve at an average distance of $0.85 \mathrm{~cm}$ from the origin of the axillary nerve.

Variation in relation of trunks and cords of
brachial plexus with major vessels: In the present study some rare variations with regard to the relations of cords of brachial plexus, median and ulnar nerves with the third part of axillary artery and brachial artery were noted in the left upper limb (1.6\%) of an adult male cadaver with approximate age of 55 years. All the three cords namely lateral, medial and posterior cords of brachial plexus were noted to be lateral to the third part of the axillary artery. It was also noted that they maintained the same relation with the first and second parts of axillary artery. The formation and branches of the three cords were found to be normal.

The ulnar nerve was noted to arise from medial cord at a lower level than usual overlapped by the junction of medial and lateral roots of median nerve. Furthermore, ulnar nerve was 
Table 1: Distance of branches of posterior cord from the parent origin.

\begin{tabular}{|c|c|c|c|c|c|c|c|c|c|c|}
\hline \multirow{3}{*}{ S. No. } & \multirow{3}{*}{$\begin{array}{l}\text { Branch of posterior } \\
\text { cord }\end{array}$} & \multicolumn{9}{|c|}{ Distances of the branches in $\mathrm{cms}$} \\
\hline & & \multicolumn{3}{|c|}{ Right } & \multicolumn{3}{|c|}{ Left } & \multicolumn{3}{|c|}{ Total } \\
\hline & & Limbs & $\begin{array}{l}\text { Studied } \\
\text { Range }\end{array}$ & $\begin{array}{l}\text { Average } \\
\text { distance }\end{array}$ & Limbs & $\begin{array}{c}\text { Studied } \\
\text { Range }\end{array}$ & $\begin{array}{l}\text { Average } \\
\text { distance }\end{array}$ & Limbs & $\begin{array}{c}\text { Studied } \\
\text { Range }\end{array}$ & $\begin{array}{l}\text { Average } \\
\text { distance }\end{array}$ \\
\hline 1 & Upper sub scapular & $28^{*}$ & $0.1-2.9$ & 0.96 & $27 *$ & $0.1-2.3$ & 0.96 & 55 & $0.1-2.9$ & 0.96 \\
\hline 2 & Thoraco dorsal & $29 *$ & $0.1-3.0$ & 1.1 & $29 *$ & $0.1-3.0$ & 1.26 & 58 & $0.1-3.0$ & 1.18 \\
\hline 3 & Lower sub scapular & $28 * *$ & $0.3-3.3$ & 1.4 & 30 & $0.2-3.2$ & 1.55 & 58 & $0.2-3.3$ & 1.47 \\
\hline 4 & Axillary & 30 & $0.7-3.9$ & 1.86 & $29 *$ & $0.8-4.1$ & 2.2 & 59 & $0.7-4.1$ & 2.03 \\
\hline 5 & Radial & 30 & $0.7-3.9$ & 1.86 & 30 & $0.8-4.1$ & 2.19 & 60 & $0.7-4.1$ & 2.02 \\
\hline
\end{tabular}

$*$ In the remaining limbs, these branches originated from the posterior division of the upper trunk; so not included here.

** In the remaining 2 limbs it originated from the axillary nerve; so not included here.

lateral to brachial artery instead of descending between axillary artery and axillary vein. Infact, ulnar nerve was found to be between the brachial artery medially and median nerve laterally. Further distribution of ulnar nerve was normal.

\section{DISCUSSION}

In the present study, all variations related to the branching pattern of brachial plexus were found only in relation to posterior cord, branching pattern of medial and lateral cords being normal in all cadavers.

The posterior cord usually gives off the upper subscapular, the lower subscapular, the thoracodorsal, and the two terminal branches i.e. the axillary and the radial nerves. The same patterns were encountered in 52 (86.67\%) limbs in the present study and in the remaining 8 (13.33\%) limbs, variations in one form or the other were encountered.

(i) The Upper Subscapular Nerve: The upper subscapular nerve usually arises from the posterior cord, but in the present study in 5 limbs $08.33 \%$ (R: L: $2: 3$ ), it originated from the posterior division of the upper trunk (root value C5, 6). Earlier, Kerr [18] had come across such a variant origin in $25.4 \%$ of his dissections and Fazan et al. [19] \& Ballesteros and Ramirez [20] had come across such a variant origin in 59\% and $50 \%$ of their dissections. No explanation can be given for such a wide discrepancy. Fazan et al [19] reported this variation to be more in males and on left side and same was found in present study also.

(ii) The Thoracodorsal Nerve

The thoracodorsal nerve is usually a branch of the posterior cord. In 2 limbs (3.33\%), it was seen to be coming from the posterior division of the upper trunk. Only Kerr [18] has been able to find such a variant origin in $1.8 \%$ of his dissections, which is comparable to the $3.33 \%$ incidence found in the present study.

(iii) The Lower Subscapular Nerve: The lower subscapular nerve took its normal origin in 58 $(96.67 \%)$ limbs but from the axillary nerve in 2 (3.33\%) limbs in the present study at a distance of $0.2 \mathrm{~cm}$ and $1.5 \mathrm{~cm}$ respectively, from the origin of the axillary nerve. Earlier, Kerr [18], Fazan et al [19]and Ballesteros, Ramirez [20]. had reported such an origin of the lower subscapular nerve from the axillary nerve in $43.31 \%, 54 \%$ and $54.4 \%$ of their dissections respectively.

(iv) The Axillary Nerve: In the sole limb, (1.66\%) of the present study, the axillary nerve was found to originate from the posterior division of the upper trunk. Earlier, Kerr ${ }^{18}$ had also found it to be so, in $9.2 \%$ of his dissections.

The Distances of Different Branches of the Posterior Cord from the Origin of the Parent Trunk: The mean value and the range of the distance of different branches of the posterior cord from the origin of the parent trunk on both the right and left sides. The distance of the origin of all the branches of the posterior cord (except the upper subscapular nerve) was more on the left side as compared to the right side, which means that the posterior cord gives its branches more distally on the left side than on the right side. In case of the upper subscapular nerve, the distance of the origin of this nerve was almost the same on the two sides. No earlier study could be traced in the accessible 
literature to compare these distances.

In the present study, though the sample size was small, every attempt has been made to discuss all the variants which were observed.

\section{Conflicts of Interests: None}

\section{REFERENCES}

[1]. Standring S, Ellis H, Healy JC, Johnson D, Williams A, Collins $P$ et al. Gray's Anatomy. In: Pectoral girdle, shoulder region and axilla. 39th $\mathrm{ed}$. El sevier Churchill Livingstone. Philadelphia. 2005; p. 8468.

[2]. Datta AK. Essentials of Human Anatomy- Superior and Inferior Extremities. In: The Axilla. $4^{\text {th }}$ ed. Current Books International. Kolkata. 2009. p. 49-52.

[3]. Brown M C, Hopkins WG and Keynes RJ. Axon guidance and target recognition. In: Essentials of neural development. Cambridge University Press. Cambridge. 1991; p. 46-66.

[4]. Williams PL, Bannister LH, Berry M M, Collins P, Dyson M , Dussek JE et al. Gray's Anatomy. In: Embryology and Development of Nervous System and Special Sense Organs. $38^{\text {th }}$ ed. Churchill Livingstone. London. 1999; p. 231-2.

[5]. Larsen WJ. Human Embryology. In. Development of limbs. $2^{\text {nd }}$ ed. Churchill Livingstone. Edinburgh. 1997; p. 311-39.

[6]. Uysal II, Seker M, Karabulut AK et al. Brachial plexus variations in human fetuses. Neurosurgery. Sep 2003; 53(3): 676-84; discussion 684.

[7]. Harry WG, Bennett JD, Guha SC. Scalene muscles and the brachial plexus: anatomical variations and their clinical significance. Clin. Anat. 1997; 10: 250-2

[8]. Abhaya A, KhannaJ and Prakash R. Variation of the lateral cord of brachial plexus piercing coracobrachialis muscle. Journal of the Anatomical Society of India. 2003;52(2):168-70.

[9]. Matejcik V. Aberrant formation and clinical picture of brachial plexus from the point of view of a neurosurgeon. Bratisl. Lek. Listy. 2003;104:291-9.

[10]. M atejcik V. Variations of nerve roots of the brachial plexus. Bratisl. Lek. Listy. 2005; 106:34-6.
[11]. Lee HY, Chung IH, Sir WS et al. Variations of the ventral rami of the brachial plexus. J. Korean Med. Sci. 1992; 7:19-24.

[12]. Matejcik V. Anatomic variations in the brachial plexus trunks and nerve roots. Rozhl. Chir. 2003; 82:456-9.

[13]. M oore KL, Persaud TV. Before we are born. The musculoskeletal system. 7th ed. Saunders Elsevier; Philadelphia. 2003; 243-4.

[14]. Morgan BA, Tabin C. Hox genes and growth: early and late roles in limb bud morphogenesis. Dev Suppl. 1994; p 181-6.

[15]. Satheesha N, Nagabhooshana S, Venkata R et al. A rare variation in the formation of the upper trunk of the brachial plexus. Neuroanatomy. 2005; 4: 37-8.

[16]. Kumar B, Vishnumaya G. Variation in the branching pattern of posterior cord of brachial plexus. J Neuro anatomy. 2008; 7:10.

[17]. Raphael DT, M clntee D, Suruda JSet al. Frontal Slah composite magnetic resonance neurography of the brachial plexus: implications for infraclavicular block approaches. J Anesthesiolog. 2005; 103:121824

[18]. Kerr AT. The brachial plexus of nerves in man, the variations in its formation and branches. Am J Anat. 1918; 23: 285-395.

[19]. Fazan VPS, Amadeu ADS, Caleffi AL et al. Brachial plexus variations in its formation and main branches. Acta Cir Bras. 2003; 18 (5): 1-8.

[20]. Ballesteros LE, Ramirez LM . Variations of the origin of the collateral branches which emerge from the posterior aspect of the brachial plexus. Journal of Brachial Plexus and Peripheral Nerve Injury. 2007; 2:14 Doi: 10.1186/1749-7221-2-14.

How to cite this article:

G Anwer Khan, Shekhar K Yadav, A Gautam, S Shakya, R Chetri. ANATOM ICAL VARIATION IN BRANCHING PATTERN OF BRACHIAL PLEXUS AND ITS CLINICAL SIGNIFICANCE. Int J Anat Res 2017;5(1):3324-3328. DOI: 10.16965/ijar.2016.459 